\title{
Coordination Strategies of Care Across Stroke Recovery: Proposals for Nursing Interventions in Primary Care
}

\author{
Queralt-Tomas Ma Ll. ${ }^{1}$, Gil-Guillen V. F. ${ }^{2}$, Clua-Espuny J. L. ${ }^{1}$, Forcadell-Arenas T. ${ }^{1}$, \\ González-Henares M. A. ${ }^{1}$, Panisello-Tafalla A. ${ }^{1}$, Ripolles-Vicente R. ${ }^{1}$, López-Pablo C. ${ }^{3}$, \\ Lucas-Noll J. ${ }^{1}$ \\ ${ }^{1}$ Primary Care Services, Health Department "Terres de 1'Ebre", Catalonian Health Institute, Tortosa, Spain \\ ${ }^{2}$ Miguel Hernández University, Family and Community Speciality, Elche, Spain \\ ${ }^{3}$ Department of Primary Care Research Institute (IDIAP) Jordi Gol, Health Department “Terres de l'Ebre”, Catalonian Health Institute, Tortosa, \\ Spain
}

\section{Email address: \\ lqueraltt.ebre.ics@gencat.cat (M. Ll. Queralt-Tomas)}

\section{To cite this article:}

Queralt-Tomas Ma L1., Gil-Guillen V. F., Clua-Espuny J. L., Forcadell-Arenas T., González-Henares M. A., Panisello-Tafalla A., Ripolles-Vicente R., López-Pablo C., Lucas-Noll J.. Coordination Strategies of Care Across Stroke Recovery: Proposals for Nursing Interventions in Primary Care. American Journal of Nursing Science. Vol. 4, No. 4, 2015, pp. 166-173. doi: 10.11648/j.ajns.20150404.14

\begin{abstract}
Background. Stroke is characterized by its complexity as a result of residual deficits, dependence in basic activities of daily living, and new needs for caregivers. The purpose of this study was to propose nursing interventions in accordance with general practice to provide continuity of care of stroke patients across the stroke-recovery trajectory and support for caregivers beyond the patient's length of stay. Methods. This is a longitudinal prospective study of a population-based cohort of all cases recorded in inpatient care of a first episode of stroke that occurred between 1 April 2006 and 31 December 2014. Results. There were 1,494 cases $(54.1 \%$ male) and the mean age was $77.4 \pm 12.9$ years. Only $27.9 \%$ were evaluated by their disability after hospital discharge. Ischemic stroke treated with thrombolysis had the best results in mortality (6.3\%) and Barthel score (85.5). Mild dependence for thrombolysis was $\mathrm{OR}=2.5$ with $\mathrm{RRR}=46 \%, \mathrm{ARR}=9.4 \%$, and $\mathrm{NNT}=10$ to get a Barthel score $>60$ at discharge. After the episode the percentage of individuals with moderate or greater dependence increased up to $22.5 \%$, with a loss $(\mathrm{p}=0.023)$ higher in women, halving the number of individuals with early independence. Of the stroke survivors $43.4 \%$ went directly home after acute care and needed a home caregiver. Age $(\mathrm{p}<0.001)$ and NIHSS $<12(\mathrm{p}=0.045)$ were identified as the only prognostic factors associated with mild dependence (Barthel $>60$ ). Conclusions. This study recommends consideration of special interests, both standardization of a discharge report as organizing an individualized primary care plan and the unification of processes for assessment of the situation of dependency among all public administrations to facilitate the necessary support planning for the stroke patient and their family in primary care.
\end{abstract}

Keywords: Stroke, Disability, Dependence, Basic Daily Activities, Caregiver, Primary Care

\section{Background}

The reasons to justify a study about stroke are based on its increasing incidence, its consequences in the form of residual deficits, dependence in basic activities of daily living, and new needs for caregivers ${ }^{1,2}$. Thus, with the progressive aging of the population, the problem's magnitude and its consequences are increasing ${ }^{3}$ However, family caregivers are often ill prepared to manage the complex problems and post-discharge care needs of stroke patients $^{4-6}$.

Therefore, after hospital discharge one of the most important aspects of care will be controls and adjustments for the patient and caregiver in disability management with the objective of minimizing the personal and family social impact up to a level as close as possible to that prior to the stroke episode, by empowering family and social reintegration of patients; and home adaptations and social resources to ensure continuity of care and patient transition between different levels of care and specialities ${ }^{7}$. In this sense, social support has been recognized as one of the most important determinants of quality of life so that the existence 
of social networks and family supports are considered a priority in care after an episode $e^{8-10}$. In our country ${ }^{11}$ the degree of dependence is evaluated on the ability to perform basic activities of daily living for the loss of physical, mental, intellectual, or sensorial autonomy, but there are no specific social support organizations available for support with widely varying results about the adherence of health professionals to recommendations, particularly patients on long-term care ${ }^{11-13}$

This work is a continuation and extension of the Ebrictus study ${ }^{14-16}$, and proposes nursing interventions in accordance with general practice to provide continuity of care of stroke patients across the stroke-recovery trajectory and support for caregivers-

\section{Methods}

It is a longitudinal study of a population-based cohort of all registered cases of a first episode of stroke that occurred between 01/04/2006 and 31/12/2014 in BaixEbre and Montsia (Tarragona, Spain). The hypothesis is that after suffering a stroke, a loss of autonomy happens, which is insufficiently described and evaluated.

\subsection{Demographic Patterns and Epidemic Characteristics}

In the last two decades the area is characterized by negative growth and a higher aging factor. The population older than 80 years old has increased $66 \%$ in the period 1986-2006, comprising $3.5 \%$ to $5.9 \%$ of the overall population. Life expectancy at birth is 81.34 years globally ${ }^{17}, 78.26$ years for men and 84.74 for women.

\subsection{Case Definition}

The definition of stroke corresponds to that set by the World Health Organization ${ }^{18,19}$. Patients were included from the automated operation of the database of patients with a diagnosis code of stroke (I60-I69). Once the inclusion criteria were confirmed, data from the clinical history of primary care (e-cap) and data from hospital records for any of the defined services (e-SAP) protocols were systematically reviewed. All primary care centers and hospitals in the area are included.

The inclusion criteria were: age $\geq 15$ up to $\leq 90$; usual residence in the territory and/or assignment to any of the participating PCs at least five years at the time of the episode of stroke; a diagnosis of stroke explicitly recorded in their medical record at any of the registration systems in health centers of the territory; should be a first stroke episode; and availability of relevant episode information in clinical records: a) outpatient clinic; b) hospital clinic; or c) access to medical/socio-sanitary reports.

\subsection{The Variables on Which Information was Collected were Grouped as Follows}

1. Socio-demographic.
2. Clinics: AVC type (ischemic or hemorrhagic stroke) and event date (day/month/year).

3. Characteristics of hospital episode: if there was inpatient care (not registered, only emergency department, hospital admission); NIHSS score (National institute of Health Stroke Scale ${ }^{20}$ ) on admission; whether or not there was thrombolytic therapy; duration of hospital stay (days).

4. Pre- and post-stroke functional autonomy: Barthel score $^{21,22}$ classified as follows: $<20$ (total dependence); 20-35 (severe dependence); 40-55 (moderate dependence); $\geq 60$ (mild dependence); or 100 (independence) registered for the pre-episode and for discharge in the medical history of the patient, hospital, or primary care.

5. Functional status of the patient at discharge: death, home-autonomous, home-address caregiver, referral to another acute hospital, or long-term centre (temporary or long-term stay).

6. Patient vital status (alive/dead), specifying the date (day/month/year) of death, if any.

7. Diagnoses-related groups ${ }^{23}$ (DRGs) in which the patient has suffered a first stroke episode are included. The DRGs are a pooling of patient morbidity. Using a computer algorithm each patient's diagnosis is recorded in the medical record in a given time period (usually a year) and a combination of diseases are reviewed and are classified in a group of nine existing categories: 1) healthy population; 2) acute disease; 3) chronic lower; 4) multiple minor chronic diseases; 5) chronic illness; 6) chronic disease in two affected organs; 7) chronic illness in three or more organs; 8) serious tumors and/or metastases; and 9) patients with greater care needs.

\subsection{Statistical Analysis}

Computerized statistical analysis was undertaken with the following: a) descriptive study basic statistics and standard deviation of key variables stratified by age and sex and b) differences in functional outcome and its evolution before and after the episode determined the possible effects on mortality and different residual deficits categorized with statistical regression model Cox. Mortality should be interpreted as overall mortality and cause-specific no stroke. Patients who died during hospitalization or within the first month are considered "immediate death". During follow-up the deceased are described as "subsequent mortality". The analysis and processing of data was performed using the SPSS 11.5 statistical package for Windows.

\section{Results}

General characteristics (table 1): 1494 patients were included (men $54.1 \%$ ). The average age was $77-4 \pm 12.9$ years (25-90). The men were significantly $(\mathrm{p}<0.001)$ lower mean age (75.4 vs. 79.9) than women. The average follow-up was $3.4 \pm 3.6$ years and $8.8 \%$ of ischemic strokes were treated with thrombolysis. 
Table 1. General characteristics (Ebrictus 2006-2014).

\begin{tabular}{|c|c|c|c|c|}
\hline Variables & Men & Women & $\mathbf{p}$ & All \\
\hline Mean age (years) & $75.4 \pm 11.8$ & $79.9 \pm 11.8$ & $<0.001$ & $77.4 \pm 12.1$ \\
\hline Sex & $808(54.1 \%)$ & $686(45.9 \%)$ & 0.023 & 1494 \\
\hline Average NIHSS score & $6.8 \pm 6.6$ & $8.8 \pm 7.6$ & \multirow{2}{*}{$<0.001$} & $7.6 \pm 7.0$ \\
\hline $\mathrm{N}(\%)$ & 378 & 233 & & $611(40.9 \%)$ \\
\hline Average Barthel score pre-stroke & $94.9 \pm 15.1$ & $90.4 \pm 20.0$ & \multirow{2}{*}{$<0.001$} & $92.9 \pm 17.7$ \\
\hline $\mathrm{N}(\%)$ & 547 & 435 & & $982(65.7 \%)$ \\
\hline Average hospital stay (days) & $8.6 \pm 9.9$ & $8.9 \pm 9.1$ & 0.615 & $8.7 \pm 9.5$ \\
\hline Average Barthel score at discharge & $84.1 \pm 24.4$ & $72.4 \pm 31.5$ & \multirow{2}{*}{$<0.001$} & $78.9 \pm 28.4$ \\
\hline $\mathrm{N}(\%)$ & 231 & 186 & & $417(24.9 \%)$ \\
\hline Average survival (years) & $3.3 \pm 2.7$ & $3.4 \pm 4.4$ & 0.433 & $3.4 \pm 3.6$ \\
\hline Number of deaths & $347(42.9 \%)$ & $339(49.4 \%)$ & 0.012 & $686(45.9 \%)$ \\
\hline Incidence rate ratio & 13.6 & 13.5 & \multirow{2}{*}{0.951} & 13.6 \\
\hline (95\% CI; 1,000 people/month) & $(12.2-15.1)$ & $(12.0-15.1)$ & & $(12.5-14.6)$ \\
\hline Ischemic Stroke & $671(83.0 \%)$ & $596(86.9 \%)$ & ns* & $1267(84.8 \%)$ \\
\hline Mean age & $75.4 \pm 11.9$ & $80.2 \pm 11.8$ & $<0.001$ & $77.6 \pm 12.1$ \\
\hline Average NIHSS score & $6.4 \pm 6.3$ & $8.7 \pm 7.6$ & \multirow{2}{*}{$<0.001$} & $7.3 \pm 7.0$ \\
\hline $\mathrm{N}(\%)$ & 328 & 215 & & $543(42.9 \%)$ \\
\hline Average hospital stay (days) & $7.9 \pm 7.9$ & $8.9 \pm 7.9$ & 0.042 & $8.3 \pm 7.9$ \\
\hline Average Barthel score at discharge & $85.0 \pm 24.3$ & $72.3 \pm 31.7$ & \multirow{2}{*}{$<0.001$} & $79.2 \pm 28.6$ \\
\hline $\mathrm{N}(\%)$ & 205 & 174 & & $379(29.9 \%)$ \\
\hline Number of deaths & $266(39.6 \%)$ & $278(46.6 \%)$ & 0.012 & $544(42.9 \%)$ \\
\hline Average survival (years) & $3.5 \pm 2.7$ & $3.7 \pm 4.5$ & $\mathrm{~ns}^{*}$ & $3.6 \pm 3.7$ \\
\hline Incidence rate ratio & & & & 12.1 \\
\hline (95\% CI; 1,000 people/month) & & & & $(11.1-13.2)$ \\
\hline Hemorrhagic Stroke & $137(17.0 \%)$ & $90(13.1 \%)$ & 0.047 & $227(15.2 \%)$ \\
\hline Mean age & $75.5 \pm 11.4$ & $77.6 \pm 12.1$ & 0.181 & $76.4 \pm 11.7$ \\
\hline Average NIHSS score & $9.6 \pm 756$ & $10.2 \pm 7.1$ & \multirow{2}{*}{0.784} & $9.8 \pm 7.4$ \\
\hline $\mathrm{N}(\%)$ & 50 & 18 & & $68(29.9 \%)$ \\
\hline Average hospital stay (days) & $11.9 \pm 15.4$ & $8.9 \pm 14.0$ & 0.161 & $10.7 \pm 14.97$ \\
\hline Average Barthel score at discharge & $76.9 \pm 24.5$ & $73.3 \pm 29.6$ & \multirow{2}{*}{0.719} & $75.8 \pm 25.9$ \\
\hline $\mathrm{N}(\%)$ & 26 & 12 & & $38(16.7 \%)$ \\
\hline Number of deaths & $81(59.1 \%)$ & $61(67.8 \%)$ & 0.119 & $142(62.6 \%)$ \\
\hline Average survival (years) & $2.16 \pm 2.4$ & $1.85 \pm 2.6$ & 0.368 & $2.0 \pm 2.4$ \\
\hline Incidence density rate & & & & 26.7 \\
\hline (95\% CI; 1,000 people/month) & & & & $(22.2-31.8)$ \\
\hline Thrombolysis Treatment & $59(8.8 \%)$ & $53(8.9 \%)$ & 0.514 & $112(8.8 \%)$ \\
\hline Mean age & $72.3 \pm 12.5$ & $72.8 \pm 12.5$ & 0.830 & $72.6 \pm 12.2$ \\
\hline Average NIHSS score & $13.0 \pm 6.4$ & $12.5 \pm 6.2$ & \multirow{2}{*}{0.66} & $12.7 \pm 6.3$ \\
\hline $\mathrm{N}(\%)$ & 55 & 47 & & $102(91.0 \%)$ \\
\hline Average hospital stay (days) & $9.9 \pm 11.6$ & $11.0 \pm 9.5$ & 0.591 & $10.4 \pm 10.6$ \\
\hline Average Barthel score at discharge & $83.9 \pm 25.0$ & $87.2 \pm 24.1$ & \multirow{2}{*}{0.591} & $85.5 \pm 24.4$ \\
\hline $\mathrm{N}(\%)$ & 33 & 31 & & $64(57.1 \%)$ \\
\hline Number of deaths & $21(35.6 \%)$ & $10(18.9 \%)$ & 0.034 & $31(27.7 \%)$ \\
\hline Average survival (years) & $2.9 \pm 2.4$ & $3.8 \pm 2.8$ & 0.089 & $3.3 \pm 2.6$ \\
\hline Incidence rate ratio & & & & 8.0 \\
\hline (95\% CI; 1,000 people/month) & & & & $(5.3-11.5)$ \\
\hline
\end{tabular}

$n s^{*}(\mathrm{p}>0.05)$

Regarding the clinical severity of the episode, a NIHSS score was registered in $40.9 \%$ of patients, $33.9 \%$ of women and $46.7 \%$ of men ( $<<0.001)$, and significant differences in the average NIHSS score by gender $(\mathrm{p}<0.001)$ were observed, with greater severity in women. The average NIHSS score was $7.6 \pm 7.0$, significantly more severe $(\mathrm{p}<0.001)$ among those who received fibrinolysis $(12.7 \pm 6.3)$.
Hemorrhagic strokes accounted for $14.8 \%$ of all strokes and $40.2 \%$ occurred in patients $\geq 80$ years of age. Of ischemic strokes, $48.4 \%$ happened in patients aged $\leq 80$ years, and they were significantly more common among men (60.2\%). Ischemic strokes, in spite of having the worst clinical profile (Table 2), had the highest average Barthel score (85.4) without cases of moderate dependence or more deficits at discharge. 
Table 2. Clinical profile severity according to type of stroke (Ebrictus 2006-2014).

\begin{tabular}{lllll}
\hline & All & Hemorrhagic & Ischemic without thrombolysis & Ischemic with thrombolysis \\
\hline $\mathrm{N}$ & 1494 & 227 & 1155 & 112 \\
Average follow-up (years) & $3.3 \pm 2.7$ & $2.0 \pm 2.4$ & $3.6 \pm 3.7$ & $3.3 \pm 2.6$ \\
Mean age (years) & $77.4 \pm 12.09$ & $76,4 \pm 11.7$ & $77.6 \pm 12.1$ & $72.6 \pm 12.25$ \\
Overall mortality (\%) & $144(10.3 \%)$ & $66(30.8 \%)$ & $78(6.6 \%)$ & $7(6.3 \%)$ \\
Home, Autonomous & $363(25.9 \%)$ & $21(9.8 \%)$ & $342(28.7 \%)$ & $34(30.4 \%)$ \\
Home, caregiver & $609(43.4 \%)$ & $51(23.8 \%)$ & $558(46.9 \%)$ & $43(38.4 \%)$ \\
Referral to acute hospital & $37(2.6 \%)$ & $22(10.3 \%)$ & $15(1.3 \%)$ & $6(5.4 \%)$ \\
Referral to chronic hospital & $247(17.6 \%)$ & $54(25.2 \%)$ & $193(16.2 \%)$ & $22(19.6 \%)$ \\
Average NIHSS score & $7.6 \pm 7.0$ & $9.8 \pm 7.4$ & $7.3 \pm 7.0$ & $12.7 \pm 6.3$ \\
Average Barthel score post-stroke & $78.9 \pm 28.4$ & $75.8 \pm 25.9$ & $79.2 \pm 28.6$ & $85.5 \pm 24.4$ \\
Percentage of patients with Barthel score $<60$ & $94 / 417(22.5 \%)$ & $10 / 38(26.3 \%)$ & $77 / 315(24.4 \%)$ & $7 / 64(10.9 \%)$ \\
\hline
\end{tabular}

The NIHSS is an independent predictor of functional outcome and correlates with the Barthel post-episode $(p=0.022)$ and survival $(p<0.001)$. In patients where there is no registered NIHSS score at discharge, the percentage of those with a Barthel value of $\leq 60$ was $39.3 \%$ and the mortality endpoint represents $55.9 \%$ of the total. The highest NIHSS score, the highest risk of Barthel score of $\leq 60$ (OR 1.14 CI95\% 1.08-1.20).

The Barthel score as pre-stroke assessment of functional status was recorded in $65.7 \%$ of the cases, but only $27.9 \%$ at discharge and for six months after. The average score before the episode (Table 1) was close to full independence
$(92.9 \pm 17.7)$ and was significantly $(\mathrm{p}<0.001)$ higher in men (94.9 vs. 90.4) than women. $79.1 \%$ were independent before the stroke and only $5.5 \%$ had a moderate or greater dependence prior. Overall, after the stroke episode the percentage of individuals in a degree of dependence at least triples. The higher age, the higher risk (OR 1.1 CI95\% 1.07-1.15), especially among women (OR 2.5 CI95\% 1.5-4.2) and this occurs by halving the number of individuals with early independence. Of stroke survivors, $43.4 \%$ go directly home after acute care and need a home caregiver and 17.6 were directly referred to long-term care (table 3).

Table 3. Vital Status at hospital discharge.Ebrictus 2006-2014).

\begin{tabular}{lllll}
\hline Vital Status at Discharge & Men & Women & p & All \\
\hline Death & $73(9.6 \%)$ & $71(11.0 \%)$ & $\mathrm{ns}^{*}$ & $144(10.3 \%)$ \\
Home, Autonomous & $204(26.9 \%)$ & $159(24.7 \%)$ & $\mathrm{ns}^{*}$ & $363(25.9 \%)$ \\
Home, caregiver & $342(45.1 \%)$ & $267(43.8 \%)$ & $\mathrm{ns}^{*}$ & $609(43.4 \%)$ \\
Referral to acute hospital & $20(2.6 \%)$ & $17(2.6 \%)$ & $\mathrm{ns}^{*}$ & $37(2.6 \%)$ \\
Referral to long-term hospital & $119(15.7 \%)$ & $128(19.8 \%)$ & $\mathrm{ns}^{*}$ & $247(17.6 \%)$ \\
Subtotal & 759 & 645 & & 1404 \\
\hline
\end{tabular}

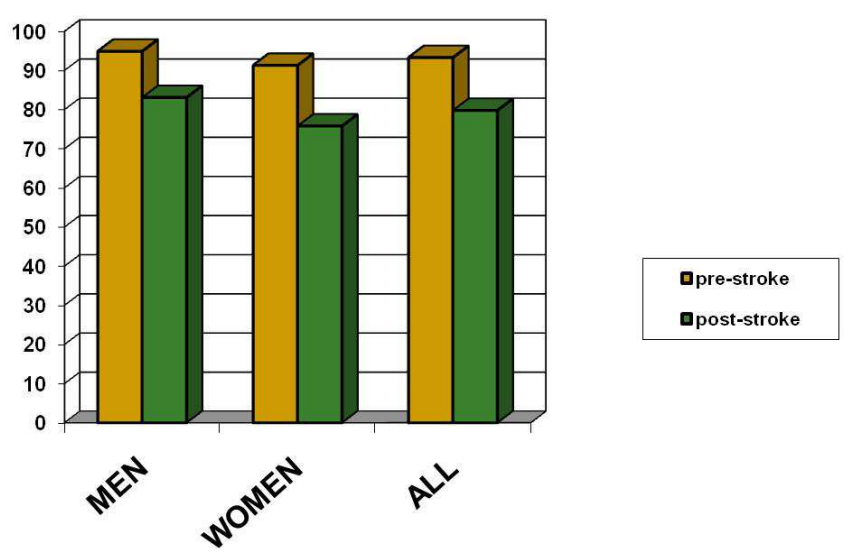

Figure 1. Barthel score (men vs women).

The percentage of patients with moderate or greater dependence increases up to $22.5 \%$, with a significant decrease $(p=0.023)$ in the Barthel score, which was higher in women than in men ( 83.18 vs. 75.8$)$, thus increasing the previous gender difference (Figure 1). The average decrease in the Barthel' score was $-14.5 \%$. The average decrease of Barthel' score at the hospital discharge in the women was $-16.9 \%$ vs $12.4 \%$ in the men, and the difference increased from $3.8 \%$ to $8.8 \%$ after the stroke episode.

There were significant differences between men and women before the stroke ( 94.9 vs $91.3, \mathrm{p} 0.002)$, and at the hospital discharge (83.1 vs 75.8, p 0.006).

A Barthel score $<60$ is a predictor of long-term mortality. Its incidence rate was 2.75 (CI95\% 1.82-4.14, $\mathrm{p}<0.001)$. In our study, thrombolysis treatment was associated with lower mortality (OR 0.67 CI95\% 0.47-0.95), less referral to long-term institutionalization in chronic centers, and had a clear protective effect (OR 0.4 CI95\% $0.18-0.98$ ) for mild dependence. The relative risk reduction was $46 \%$, the absolute risk reduction was $9.4 \%$ to get a reduction in the number of people with the outcome of a Barthel score $<60$ at discharge, and the number needed to treat was 10 to get one more result with a Barthel score $>60$ at discharge. Age (OR 1.07 CI95\% 1.01-1.13) and NIHSS score (OR 1.1 CI95\% 1.04-1.18) were 
identified as the only independent prognostic protector factors to dependence (Barthel $<60)$.

Finally, $92.2 \%$ of stroke patients were concentrated in groups 6 and 7 in the Diagnoses Related Groups classification (table 4). Although there were no significant differences in the total group, in group 6 the percentage $(41.1 \%)$ of men was significantly higher $(\mathrm{p}=0.002)$ than women $(30.0 \%)$.

Table 4. Clinical Risk Groups Results.

\begin{tabular}{lllll}
\hline Clinical Risk Groups & Men & Women & p & \\
\hline & & & \\
1 & - & 1 & ns* & 1 \\
2 & 1 & 2 & & 3 \\
3 & - & 1 & & 1 \\
4 & - & 1 & $\mathrm{~ns}^{*}$ & 1 \\
5 & $27(6.1 \%)$ & $10(3.3 \%)$ & $\mathrm{ns}^{*}$ & $37(4.7 \%)$ \\
6 & $317(71.2)$ & $237(71.0 \%)$ & $\mathrm{ns} *$ & $554(71.1 \%)$ \\
7 & $86(19.3 \%)$ & $78(23.4 \%)$ & $\mathrm{ns} *$ & $164(21.1 \%)$ \\
8 & $10(2.2 \%)$ & $4(1.2 \%)$ & $\mathrm{ns}^{*}$ & $14(1.8 \%)$ \\
9 & $3(0.7 \%)$ & 0 & $3(0.4 \%)$ \\
Subtotal & 445 & 334 & 779 \\
\hline
\end{tabular}

\section{Discussion}

The main evidence from this study is the enormous impact of an episode of stroke on people's autonomy. Currently, our healthcare system has a lot of clinical and prognostic information that is stratified into different levels of care (hospital, primary care) and different providers (social assistance, dependency law, welfare department, etc.) which paradoxically makes assessment planning and resolution of specific needs of affected patients more difficult. Nursing has a very important and necessary role in making this transition easier and smoother. Family caregivers of stroke survivors who are just beginning their role must learn new skills and incorporate new knowledge into their daily activities and should get the right social support.

We should point out the main facts we have found in this study: the assessment of functional status for basic ADL is recorded in only $27.9 \%$ of the cases at discharge and for six months after episode in the primary care database; the worse the severity of the episode, the greater the probability that no NIHSS score was registered at discharge; the classification by DRGs has little utility to provide qualitative data on functional impairment; and the individual Care Program by the Social Welfare Department 11 is not worked out until the evidence of dependence level has not been defined by one tool which is different from the ones used by the clinical organization at discharge 20 . If around $50 \%$ of stroke survivors go directly home after acute care, family caregivers play a central role in supporting them in their transition through rehabilitation and return to community living 24 while that empty time. We think these facts are barriers to acquiring effective implementation of stroke care pathways and stroke family support programs. It constitutes an approach based more to the characteristics of the care provider than to the patient needs.

The first step would be to get a comprehensive pre-discharge report of the patient that included an assessment of caregivers. Nurses should explore care coordination and care management acknowledging that families have limited participation in the discharge planning process. We suggest the availability of standardized hospital discharge reports that include all variables related to the episode of stroke to provide epidemiological, clinical, disability outcomes, and prognosis of stroke episode. Both in hospitals and in primary care, included social services, an appropriate assessment of both the episode and its effects on ADL should be linked to clinical objectives and quality records. We consider the followingbasic and necessary content in a hospital discharge report:

1. Type of stroke.

2. History of previous stroke and risk of relapse: Essen scale.

3. Possible cause: aging population, increased antiplatelet and anticoagulant treatment, and episodes of stroke (traumatic) not necessarily related to traditional cardiovascular risk factors (such as falls) involving different preventive care.

4. Episode severity: NIHSS/Rankin; clearly the Barthel scale provides more specific and detailed information on the patient's needs, while the Rankin scale is more comprehensive and useful in the decision of thrombolytic therapy evaluation.

5. Impact on ADL: Barthel, immediately before the post-stroke and developmental period.

6. If it has been started, the rehabilitation process in a specific service or home and what are the functional impairments.

7. Outcomes and quality of care expected (swallowing, $\mathrm{SNG}$, depression, etc.). A care pathway post-stroke in the context of complex illness would be useful. This should include both pharmacological and non-pharmacological aspects to allow design of a strategic plan to follow-up in primary care.

8. If there has been a resulting death, it has the same relationship to the episode of stroke (traumatic or intercurrent complications such as aspiration pneumonia or ischemic miocardiopathy), allowing access to information regarding quality of care and improving registration of the causes of mortality.

9. The family and/or caregivers have been informed about social networks and stroke assistance in the territory: social 
work, law dependence, rehabilitation center, for cognitive activities' centers, day hospitals, residential and day centers, home care services, etc.

The cases with greater clinical severity and worse prognosis have discharge reports without variables such as Barthel or NIHSS because they mean $40 \%$ of the cases with a Barthel value of $\leq 60$ or the mortality endpoint is $55.9 \%$. If we do not have information we cannot provide both stroke-specific information and caregiver training and counseling, or get social support. This reflects an information lack which is a barrier to acquiring effective implementation of stroke care pathways and stroke family support programs. Supposedly it reflects poor quality of medical records because it is more likely that the absence of information in medical records corresponds to unperformed interventions rather than performed but not informed interventions. We did not perform analyses to determine whether mortality rates were related to quality of care.

The second step would be to design comprehensive care coordination and case management, smoothing their transition from having intense therapy after hospital discharge to having little or no assistance as home caregiver. The needs of other chronic conditions must be included. Given the Social Welfare Department11 defines and rules one individual Patient Care Program (PIA) very long after the discharge, this failure to identify needs of both patients and caregivers and objectives always generates setbacks and holds up action, causing delays and lack of continuity in the coordination of the health and social services. Why don't make the Patient Care Plan together?

Also, the use of a primary Care patient Plan to follow and support family caregivers with daily activities should include:

1. Periodic assessment of residual disability in activities of daily living (Barthel/Rankin).

2. Quality of life (SF-36)25: to explore the impact of stroke on patients' QoL and their caregivers and the efficacy of interventions.

3. Handling of Disability: RHB, care transitions, changes and adaptations in the home, primary care and specialist follow-up, on medication self-management, and knowledge of signs/symptoms of exacerbations.

4. Prevention of immobility complications: abnormal positions, thromboembolism prevention, and pressure sores.

5. Nutritional state; risk of aspiration.

6. Ending harmful habits.

7. Handling problems with sphincters.

8. Sexual activity.

9. Aphasia and possible consequences of communication deficit.

10. Caregiver health is closely linked to the stroke patient's physical, cognitive, and psychological recovery.

The effectiveness of advanced registered nurse practitioners compared to routine visits from a home health nurse for fewer re-hospitalizations and lower costs post-discharge has been consistently demonstrated 26 . In addition, follow-up post-discharge and supportive counseling interventions individualized to the caregiver's needs should be implemented. The aging of our population is associated with a higher prevalence of comorbidities. It is necessary to identify at discharge especially those patients susceptible to accidents, treated with OAC, polypharmacy and control problems, use and/or identification of prescribed medicines by the lack or loss of physical, mental, intellectual or sensory functions, or characteristics of their autonomous living environment.

Diagnosis-related groups are increasingly being used for various purposes in many countries. However, there are no studies comparing different DRG systems in the care of stroke. Actually, its utility seems relatively quite short because it is not associated with proportionately greater degrees of disability and is less discriminative of the intensity or quality of the affected functions 27.

Eventually, the records should measure the recovery of survivors over time and their needs in terms of social and medical services. Nurses must be involved in research about results in patient outcomes. Adding web-based services, leading support groups and educational resources, and managing telehealth monitoring would make the intervention more comprehensive while minimizing resource use and improving accessibility.

There are some limitations to our study. First, it consisted of a retrospective review of medical records. Only that information available on the records was considered, and when information was lacking the intervention was declared "no achieved." Therefore, the results represent the worst possible scenario and might underestimate the real adherence to the selected measures. When analyzing a complex intervention, such the principal characteristics of existing practices, it is relevant to consider the management of information involved in the process as key element that should be common and shared between hospital and community to grant the continuity of care and a coordinated use of resources.

\section{Conclusion}

1. After first stroke, $43.4 \%$ of stroke survivors go directly home and the percentage of patients in each degree of dependency triples with higher lost in the previous Barthel score among women (7.3) than in men (3.6).

2. Regarding the average assessment of functional status (Barthel score), this variable is recorded in only $27.9 \%$ of all cases in the hospital discharge reports as specific indicators in primary care. The NIHSS score was registered in $40.9 \%$ of patients.

3. We consider alternatives of special interest both the standardization of hospital discharge reports as well as the transfer of care from having intense therapy to having little or no assistance after hospital discharge. Nurses should explore care coordination and care management recognizing that family had limited participation in the discharge planning process.

4. The nurse leadering social support groups' information about and educational resources and identifying at discharge especially those fragile patients often jeopardized by 
multifactorial risk as falls, polypharmacy, ACO, solitude, cognitive impairment, etc. in order to facilitate his access to the wide catalogue of services that could be provided by an integrated care system.

5. The simplification and sharing of all the evaluation processes of dependence is necessary by public administration to avoid repetitions with different instruments and routes from different sources.

\section{Acknowledgements}

We would like to thank the Clinical Evidence Based Medicine and Emotional Department, Miguel Hernández University, Elx, Spain for its support in developing this research.

\section{References}

[1] Feigin, V. L., Forouzanfar, M. H., Krishnamurthi, R., Mensah, G. A., Connor, M., Bennett, D. A., GBD Stroke Experts Group. (2014). Global and regional burden of stroke during 1990-2010: Findings from the global burden of disease study 2010. Lancet, 383(9913), 245-254.

[2] Ma, V. Y., Chan, L., \& Carruthers, K. J. (2014). The incidence, prevalence, costs and impact on disability of common conditions requiring rehabilitation in the US: Stroke, spinal cord injury, traumatic brain injury, multiple sclerosis, osteoarthritis, rheumatoid arthritis, limb loss and back pain. Archives of Physical Medicine and Rehabilitation, 95(5), 986-995. doi: 10.1016/j.apmr.2013.10.032.

[3] Serrano-Villar, S., Fresco, G., Ruiz-Artacho, P., Bravo, A., Valencia, C., Fuentes-Ferrer, M., Porta-Etessam, J. (2013). Stroke in the very old: Myths and realities. Medicina Clínica, 140(2), 53-8. doi: 10.1016/j.medcli.2012.05.036.

[4] Chiu, S. Y., Livneh, H., Tsao, L. L., \& Tsai, T. Y. (2013). Acceptance of disability and its predictors among stroke patients in Taiwan. BMC Neurology, 13, 175. doi: 10.1186/1471-2377-13-175.

[5] O’Donnell, M.J., Fang, J., D’Uva, C., Saposnik, G., Gould, L., McGrath, E., Investigators of the Registry of the Canadian Stroke Network. (2012). The PLAN Score: A bedside prediction rule for death and severe disability following acute ischemic stroke. Archives of Internal Medicine, 172(20), 1548-1556. doi: 10.1001/2013.jamainternmed.

[6] Meader, N., Moe-Byrne, T., Llewellyn, A., \& Mitchell, A. J. (2014). Screening for poststroke major depression: A meta-analysis of diagnostic validity studies. Journal of Neurology, Neurosurgery, and Psychiatry, 85(2), 198-206. doi: 10.1136/jnnp-2012-304194.

[7] Gasparetto T., Toffanin R., Santacaterina M., Baggio P., Greselin L., Saugo M., Pertile C., Zamburlin R. C., Larsen T (2011). COPD, HF, Stroke: Economic and legal barriers to hospital-community integration. University of Southern Denmark. www.integratedhomecare.eu. (20/Dec/2014, $11: 30 \mathrm{~h})$

[8] Taylor-Piliae, R. E., Hoke, T. M., Hepworth, J. T., Latt, L. D., Najafi, B., \& Coull, B. M. (2014). The effect of TaiChi on physical function, fall rates and quality of life among older stroke survivors. Archives of Physical Medicine and Rehabilitation, 95(5), 816-824. doi:10.1016/j.apmr.2014.01.001.

[9] Kruithof, W. J., van Mierlo, M. L., Visser-Meily, J. M., van Heugten, C. M., \& Post, M. W. (2013). Associations between social support and stroke survivors' health related quality of life. A systematic review. Patient Education and Counseling, 93(2), 169-176. doi: 10.1016/j.pec.2013.06.003.

[10] Cameron, J. I., Naglie, G., Gignac, M. A. M., Bayley, M., Warner, G., Green, T., Cheung, A. M. (2014). Randomized clinical trial of the timing it right stroke family support program: research protocol. BMC Health Services Research, 14, 18. doi:10.1186/1472-6963-14-18.

[11] Ministerio de Sanidad, Política social e Igualdad. (2011). Reial Decret 174/2011 d'11 de febrer. BOE 18.02.2011, número 42. http://benestar.gencat.cat/ca/ambits_tematics/persones_amb_d ependencia/dades_dependencia (revised 01/03/2015, 15:00)

[12] Donnellan, C., Sweetman, S., \& Shelley, E. (2013). Health professionals' adherence to stroke clinical guidelines: A review of the literature. Health Policy, 111(3), 245-263. doi: 10.1016/j.healthpol.2013.05.002.

[13] Gache, K., Leleu, H., Nitenberg, G., Woimant, F., Ferrua, M., \& Minvielle, E. (2014). Main barriers to effective implementation of stroke care pathways in France: a qualitative study. BMC Health Services Research, 14, 95. doi: 10.1186/1472-6963-14-95.

[14] Clua-Espuny, J. L., Piñol-Moreso, J. L., Panisello-Tafalla, A., Lucas-Noll, J. Gil-Guillen, V. F., Orozco-Beltran, D., \& Queralt-Tomas, M. L. (2012). Estudio Ebrictus. Resultados funcionales, supervivencia y años potenciales de vida perdidos después del primer episodio de ictus. Atención Primaria, 44(4), 223-231. doi: 10.1016/j.aprim.2011.04.004.

[15] Clua-Espuny, J. L., Piñol-Moreso, J. L., Gil-Guillén, J. F., Orozco-Beltran, D., Panisello-Tafalla, A., \& Lucas-Noll, J. (2012). La atención sanitaria del ictus en el área Terres de l'Ebre desde la implantación del Código Ictus: Estudio Ebrictus. Medicina Clínica, 138, 609-611. doi: 10.1016/j.medcli.2011.10.004.

[16] Queralt-Tomas MLL. (2015). Coordination strategies of care acreoo stroke recovery: proposals for nursing interventions in primary care. Clinical Nursing Sudies, 3(2), 1-9. DOI 10.5430/cns.vXnXnXX.

[17] Departament de Salut. Generalitat de Catalunya. (2008). Anàlisi de la mortalitat a Catalunya. Retrieved from http://www.gencat.cat/salut/depsalut/html/ca/dir1932/index.ht $\mathrm{ml}$.

[18] Pla Director de Malalties de l'Aparell Circulatori-Malaltia Vascular Cerebral Agència d'Avaluació de Tecnologia i Recerca Mèdiques (AATRM). (2005). Guia de práctica clínica ictus. Barcelona.

[19] Albers, W., Clarck, M., \& Madden, P. (2002). ATLANTIS trial: Results for patients treated within 3 hours of stroke onset. Alteplase Thrombolysis for Acute Noninterventional Therapy in Ischemic Stroke. Stroke, 33, 493-495.

[20] Adams HP, Davis PH, Leira EC, Chang KC, Bendixen BH, Clarke WR, et al (1999). Baseline NIH stroke scale score strongly predicts outcome after stroke: A report of the Trial of Org 10172 in acute stroke treatment (TOAST). Neurology, 53:123-31. 
[21] van Exel, N. J., Scholte op Reimer, W. J., \& Koopmanschap, M. A. (2004). Assessment of post-stroke quality of life in cost-effectiveness studies: The usefulness of the Barthel Index and the EuroQoL-5D. Quality of Life Research, 13(2), 427-433.

[22] Kwok, T., Lo, R. S., Wong, E., Wai-Kwong, T., Mok, T., \& Kai-Sing, W. (2006). Quality of life of stroke survivors: A 1-year follow-up study. Archives of Physical Medicine and Rehabilitation, 87, 1177-1182.

[23] Sisap-eCap. (2013). Seguiment d'indicadors clínics dels professionals d'atenció primària. SAP Terres de l'Ebre. Retrieved from http://p0019.cpd1.grupics.intranet/sisap/Individual/crg.

[24] Magalhães, R., Abreu, P., Correia, M., Whiteley, W., Silva, M. C., \& Sandercock, P. (2014). Functional status three months after the first ischemic stroke is associated with long-term outcome: Data from a community-based cohort. Cerebrovascular Diseases, 38, 46-54. doi: 10.1159/000364938.

[25] Ann-Helene Almborg, Stig Berg. (2009). Quality of life among Swedish patients after stroke: psychometric evaluation of SF-36. J Rehabil Med 2009; 41: 48-53.

[26] Naylor, M. D., Brooten, D., Campbell, R., Jacobsen, B. S., Mezey, M. D., Pauly, M. V., \& Schwartz, J. S. (1999). Comprehensive discharge planning and home follow-up of hospitalized elders: A randomized clinical trial. Journal of the American Medical Association, 281(7), 613-620.

[27] Peltola, M., \& Quentin, W. (2013). Diagnosis-related groups for stroke in Europe: patient classification and hospital reimbursement in 11 countries. Cerebrovascular Diseases, 35, 113-123. doi:10.1159/000346092. 